\title{
Promoviendo los estilos de vida saludable en las comunidades campesinas
}

Las comunidades campesinas del Perú, representan un valor histórico y cultural, sin embargo a lo largo de los años han recibido una serie de influencias en el marco de la modernidad y de las políticas de estado, que benefician su desarrollo socio-ambiental pero que a su vez ponen en riesgo su salud y la de sus familiares.

Dada la dedicación natural a sus actividades comunales centradas en la artesanía, ganadería, el cultivo y producción de la tierra, sin percibirlo, exponen su salud de manera cotidiana, situación que ha sido observada desde los años 90 por la Facultad de Enfermería de la Universidad Peruana Cayetano Heredia, e intervenida con un plan de acciones de salud comunitaria a través de su programa académico de pregrado cuyo componente central en la formación de los nuevos profesionales de enfermería tiene como área de desarrollo la promoción y la prevención de la salud de la persona, familia y grupos, considerando la prioridad de sus necesidades desde la perspectiva de la población (1).

La Facultad de Enfermería, basada en las normativas ministeriales del sector salud y de las comunidades campesinas ha elaborado una propuesta académica a ejecutar en el marco de un convenio distrital y a través del curso del internado de enfermería, el asumir la responsabilidad de un trabajo rural e interdisciplinario enfermería - psicología, con enfoque preventivo promocional, con la finalidad de implementar un programa de estilos de vida saludable en algunas comunidades campesinas de las zonas rurales de Lima, garantizando con ello de manera integral, la armonía entre el respeto a su cultura y el estado de bienestar físico y emocional de las personas según su ciclo vital.

Para garantizar el cumplimiento de los objetivos de la propuesta, las internas de enfermería iniciaran su intervención con las comunidades campesinas, con permanencia en rotaciones bimensuales, bajo la supervisión de docentes calificados de la universidad. Así mismo en la propuesta se incluirán actividades de atención directa, docencia y administración en el marco de un cronograma diario.

También se contará con la participación de los alumnos de psicología a través de visitas domiciliarias e intervenciones en los colegios cada quince días.

Las situaciones de emergencias y problemas de salud, serán atendidos en coordinación con los establecimientos de salud, así mismo el fomento de habilidades comunicacionales y de relaciones interpersonales, el control de crecimiento y desarrollo del niño sano, programa de vacunaciones, programas educativos y creación de clubes de niños, jóvenes y adultos mayores (2).

Mg. Gianina Farro Peña 